\title{
Performance in Olympic triathlon: changes in performance of elite female and male triathletes in the ITU World Triathlon Series from 2009 to 2012
}

Christoph Alexander Rüst ${ }^{1}$, Romuald Lepers ${ }^{2}$, Michael Stiefel ${ }^{1}$, Thomas Rosemann ${ }^{1}$ and Beat Knechtle ${ }^{1,3,4^{*}}$

\begin{abstract}
This study investigated the changes in performance and sex difference in performance of the world best triathletes at the ITU (International Triathlon Union) World Triathlon Series (i.e. $1.5 \mathrm{~km}$ swimming, $40 \mathrm{~km}$ cycling and $10 \mathrm{~km}$ running) during the 2009-2012 period including the 2012 London Olympic Games. Changes in overall race times, split times and sex difference in performance of the top ten women and men of each race were analyzed using single and multi-level regression analyses. Swimming and running split times remained unchanged whereas cycling split times $(B=0.003, P<0.001)$ and overall race times $(B=0.003, P<0.001)$ increased significantly for both women and men. The sex difference in performance remained unchanged for swimming and cycling but decreased for running $(B=-0.001, P=0.001)$ from $14.9 \pm 2.7 \%$ to $13.2 \pm 2.6 \%$ and for overall race time $(B=-0.001, P=0.006)$ from $11.9 \pm 1.2 \%$ to $11.4 \pm 1.4 \%$. The sex difference in running $(14.3 \pm 2.4 \%)$ was greater $(P<0.001)$ compared to swimming $(9.1 \pm 5.1 \%)$ and cycling $(9.5 \pm 2.7 \%)$. These findings suggest that $(i)$ the world's best female short-distance triathletes reduced the gap with male athletes in running and total performance at short distance triathlon with drafting during the 2009-2012 period and (ii) the sex difference in running was greater compared to swimming and cycling. Further studies should investigate the reasons why the sex difference in performance was greater in running compared to swimming and cycling in elite short-distance triathletes.
\end{abstract}

Keywords: Endurance; Performance; Sex difference; Swimming; Cycling; Running

\section{Background}

Triathlon is a multi-sports discipline involving swimming, cycling and running and can be held from the Olympic distance (i.e. $1.5 \mathrm{~km}$ swimming, $40 \mathrm{~km}$ cycling and $10 \mathrm{~km}$ running) (Bentley et al., 2002) to the Ironman distance (i.e. $3.8 \mathrm{~km}$ swimming, $180 \mathrm{~km}$ cycling and $42.195 \mathrm{~km}$ running) such as the 'Ironman Hawaii' (Lepers, 2008; Lepers et al., 2013). Recent studies showed that triathlon performances changed over the last decades for both the Olympic distance (Etter et al., 2013) and the Ironman distance (Lepers, 2008; Rüst et al., 2012a, 2012b).

\footnotetext{
* Correspondence: beat.knechtle@hispeed.ch

${ }^{1}$ Institute of General Practice and for Health Services Research, University of Zurich, Zurich, Switzerland

${ }^{3}$ Gesundheitszentrum St. Gallen, St. Gallen, Switzerland

Full list of author information is available at the end of the article
}

Etter et al. (2013) showed for short-distance triathlon at national level during the $2000-2010$ period that the overall top five women improved overall race time by $\sim 0.8$ min per annum, while overall race time remained stable in men. During this period, swimming and running performances remained stable for both women and men while cycling performance decreased significantly by $\sim 0.8 \mathrm{~min}$ per annum in women and by $\sim 0.5 \mathrm{~min}$ per annum in men, respectively. Similarly, in a long-distance triathlon at national level such as 'Ironman Switzerland' as a qualifier Ironman for the Ironman World Championship 'Ironman Hawaii', Rüst et al. (2012a) observed that women improved between 1995 and 2011 in all three split disciplines and overall race times whereas men improved only in the cycling split and in overall race time. In 'Ironman Hawaii', the world best elite men improved in the three split times and overall race time, whereas women 
improved only in cycling, running and overall race time during the last 30 years (Rüst et al., 2012b). An increase in running speed for both ITU (International Triathlon Union) male and female junior elite triathletes has been reported since the introduction of sprint distance events (i.e. $750 \mathrm{~m}$ swimming, $20 \mathrm{~km}$ cycling and $5 \mathrm{~km}$ running) at the World Championships 2002 to 2011 (Landers et al., 2013; Vleck et al., 2008). To date, the changes in performance of the world best elite triathletes in short distance triathlon have not been investigated.

The sex difference in triathlon performance has changed during the last decades. For example, the sex difference in overall race time in 'Ironman Hawaii' decreased significantly during the last 25 years to stabilize at $~ 11.3 \%$ (Lepers, 2008). During the same period, the sex difference in performance remained quite stable for swimming ( 12.5\%) and cycling ( 12.5\%) but it decreased for running from $\sim 13.5 \%$ to $\sim 7.3 \%$ (Rüst et al., 2012b). At the long-distance duathlon World Championship 'Powerman Zofingen' from 2002 to 2011, the sex differences in performance were $\sim 16 \%, \sim 17 \%, \sim 15 \%$, and $\sim 16 \%$ for the $10-\mathrm{km}$ running split, the $150-\mathrm{km}$ cycling split, the $30-\mathrm{km}$ running split and overall race time, respectively (Rüst et al., 2013).

The sex difference in triathlon performance depends upon different variables such as the three disciplines, the distances (i.e. short-distance versus long-distance), race tactics (Landers et al., 2008), training (Etxebarria et al., 2013), race experience (Gilinsky et al., 2013), age (Knechtle et al., 2012), anthropometric characteristics (Knechtle et al., 2010a, 2010b), and the level of the triathletes (i.e. elite versus non-elite) (Lepers et al., 2013). For example, in short-distance triathletes at national level, the sex difference appeared greater for running ( 17\%) compared to swimming ( 15\%) and cycling ( 13\%) (Etter et al., 2013). In contrast for elite long-distance triathletes, the sex difference in performance tended to be lower for running and swimming compared to cycling (Lepers, 2008).

Anthropometric characteristics seem to be important predictors for race time in short distance triathlon at world class level (Landers et al., 2000). Potential reasons in the differences in performance between female and male triathletes are the lower maximum oxygen uptake in women $\left(\sim 52.8 \mathrm{ml} \cdot \mathrm{kg}^{-1} \cdot \mathrm{min}^{-1}\right)$ compared to men $\left(\sim 61.3 \mathrm{ml} \cdot \mathrm{kg}^{-1} \cdot \mathrm{min}^{-1}\right)$ (Knechtle et al., 2004), the lower muscle mass in women $(\sim 28 \mathrm{~kg})$ compared to men ( 41 kg) (Knechtle et al., 2010a), and the higher percent body fat in women ( 23.6\%) compared to men $(\sim 13.7 \%)$ (Knechtle et al., 2010a). If we consider the three individual sports, there is a greater difference between the male and female world records for running (e.g. $10 \mathrm{~km}$ running difference $\sim 12.1 \%, 21.1 \mathrm{~km}$ running difference $\sim 12.8 \%$ ) than swimming (e.g. 1,500 m swimming difference $~ 7.4 \%$ ) and cycling (e.g. cycle hour record difference $\sim 7.9 \%)$. The difference between running and the two other disciplines could be explained in part by the biological gender difference in relative body fatness which is higher in women (Landers et al., 1999). Indeed, greater body fat may represent a limit in weight-bearing activities such as running.

In addition, at international level, the differences in performance for elite triathletes between short- and longdistance triathlon might be explained by the possibility of drafting in the cycling split. In international long-distance triathlon, drafting is prohibited in contrast to shortdistance triathlons of the ITU World Triathlon Series. Drafting in swimming and cycling may result in a better tactical approach to increase the overall performance in elite Olympic distance triathlons (Bentley et al., 2008). Pacing strategies are observed by elite athletes who are swimming or cycling in a sheltered position inducing several changes of pace (Hausswirth and Brisswalter, 2008). Drafting may alter the sex difference in cycling and in the subsequent running performance. Fast runners seemed to benefit most from drafting during cycling (Hausswirth et al., 1999). For the run split in a short-distance triathlon, an appropriate pacing appeared to play a key role in high-level triathlon performance (Le Meur et al., 2009). Le Meur et al. (2009) showed that both female and male elite triathletes developed specific pacing strategies in running. The men's running speed decreased significantly over the whole distance whereas women slowed down in the up- and down-hill sections.

Elite short-distance triathletes intending to compete in the Olympic Games need to undergo a qualification in the four years before the Olympic Games. They have to compete in the ITU World Triathlon Series in order to obtain points to qualify for the 55 start places in the Olympic Games. To date, the changes in performance of world class triathletes during a 4-year period before the Olympic Games have not been analyzed. The first aim of the study was therefore to analyze the changes in performance for both elite men and women and the corresponding sex difference in performance in the ITU World Triathlon Series between 2009 and 2012 including the Olympic Games 2012 in London. A second aim was to investigate the sex difference in performance for overall race time and for split times in these athletes.

\section{Methods}

All procedures used in the study met the ethical standards of the Swiss Academy of Medical Sciences and were approved by the Institutional Review Board of Kanton St. Gallen, Switzerland, with a waiver of the requirement for informed consent of the participants given the fact that the study involved the analysis of publicly available data. 


\section{Data sampling and data analysis}

The data set for this study was obtained from the website of ITU World Triathlon Series (http://wts.triathlon.org/). Overall race times and split times (i.e. $1.5 \mathrm{~km}$ swimming, $40 \mathrm{~km}$ cycling and $10 \mathrm{~km}$ running) over the years in all women and men in the ITU World Triathlon Series between 2009 and 2012 were collected. Races in 2012 were only considered before the Olympic Games. Transition times between swimming and cycling as well as between cycling and running were included in the overall race time. For the first ten women and men in each race, the change in overall race time and split times as well as the sex difference was determined. The sprint distance races (i.e. $750 \mathrm{~m}$ swimming, $20 \mathrm{~km}$ cycling and $5 \mathrm{~km}$ running) in the ITU World Triathlon Series were not considered.

\section{Statistical analysis}

In order to increase the reliability of the data analyses, each set of data was tested for normal distribution as well as for homogeneity of variances prior to statistical analyses. Normal distribution was tested using a D'Agostino and Pearson omnibus normality test and homogeneity of variances was tested using a Levene's test. Regression analysis was used to find significant changes in a variable across years. A hierarchical regression model was used to avoid the impact of a cluster-effect on results in case one athlete finished more than once in the top ten in a race. A Kruskal-Wallis test with Dunn's test for multiple comparisons was performed after pooling of all data across years to test whether the sex difference differed between the three disciplines. Statistical analyses were performed using IBM SPSS Statistics (Version 19, IBM SPSS, Chicago, IL, USA) and GraphPad Prism (Version 5, GraphPad Software, La Jolla, CA, USA). Significance was accepted at $P<0.05$ (two-sided for $t$-tests). Data in the text and in the figures are given as mean \pm standard deviation (SD).

\section{Results}

Between 2009 and 2012, 58 different women and 55 different men recorded a top ten result in a total of 27 World Triathlon Series event and the 2012 Olympic Games. Eight races were held in 2009, seven races in 2010, eight races in 2011 and four races in 2012 before the 2012 Olympic Games. Table 1 reports the number of finishes during the studied period.

Figure 1 shows the changes in overall race times and split times across all 28 races. For women and men, the split times in swimming and running remained unchanged. The cycling split times increased for women from $63.5 \pm 3.0 \mathrm{~min}$ to $67.2 \pm 2.3 \mathrm{~min}$ and for men from $57.4 \pm 2.6 \mathrm{~min}$ to $60.4 \pm 1.1 \mathrm{~min}$ (Table 2 ) also when corrected for multiple finishes (Table 3 ). Overall race times increased for women from $119.5 \pm 3.4 \mathrm{~min}$ to $123.3 \pm$ $2.9 \mathrm{~min}$ and for men from $106.9 \pm 3.6 \mathrm{~min}$ to $110.6 \pm$
Table 1 Number of top ten finishers and finishes between 2009 and 2012

\begin{tabular}{lccc}
\hline Number & Women & Men & Overall \\
\hline Finishers & 58 & 55 & 113 \\
Total finishes & 270 & 270 & 540 \\
1 Finish & 13 & 18 & 31 \\
2 Finishes & 12 & 9 & 21 \\
3 Finishes & 6 & 6 & 12 \\
4 Finishes & 6 & 3 & 9 \\
5 Finishes & 4 & 0 & 4 \\
6 Finishes & 5 & 1 & 6 \\
7 Finishes & 2 & 4 & 6 \\
8 Finishes & 0 & 1 & 1 \\
9 Finishes & 3 & 2 & 5 \\
10 Finishes & 1 & 1 & 2 \\
$>10$ Finishes & 6 & 10 & 16 \\
\hline
\end{tabular}

2.2 min (Table 2) also when corrected for multiple finishes (Table 3). The sex difference in performance remained unchanged for swimming and cycling but decreased for running from $14.9 \pm 2.7 \%$ to $13.2 \pm 2.6 \%$ and for overall race time from $11.9 \pm 1.2 \%$ to $11.4 \pm 1.4 \%$ (Table 2) also when corrected for multiple finishes (Table 4). The sex difference in running $(14.3 \pm 2.4 \%)$ was significantly $(P<0.001)$ greater compared to the sex difference in swimming $(9.1 \pm 5.1 \%)$ and cycling $(9.5 \pm$ 2.7\%) (Figure 2).

\section{Discussion}

The aim of this study was $(i)$ to analyze the changes in performance and sex difference for both elite women and men in the ITU World Triathlon Series between 2009 and 2012 including the Olympic Games 2012 in London and $(i i)$ to investigate the sex difference in performance for overall race time and split times in these athletes. The present findings showed an increase in overall race times and cycling split times between 2009 and 2012 for the top ten finishers in the ITU World Triathlon Series including the 2012 Olympic Games.

However, due to several limitations, e.g. different races each year, different environmental conditions, and potential differences in the course lengths, these changes in cycling and total performance across the period 2009-2012 may be not relevant. Additionally, in most cases, the female and male events were not only held at different times of the day but also on different days. Besides these limitations, the most interesting findings were $(i)$ a decrease in the sex difference for running and overall race time with a stabilization in swimming and cycling and (ii) a greater sex difference in running compared to cycling and swimming performances. 

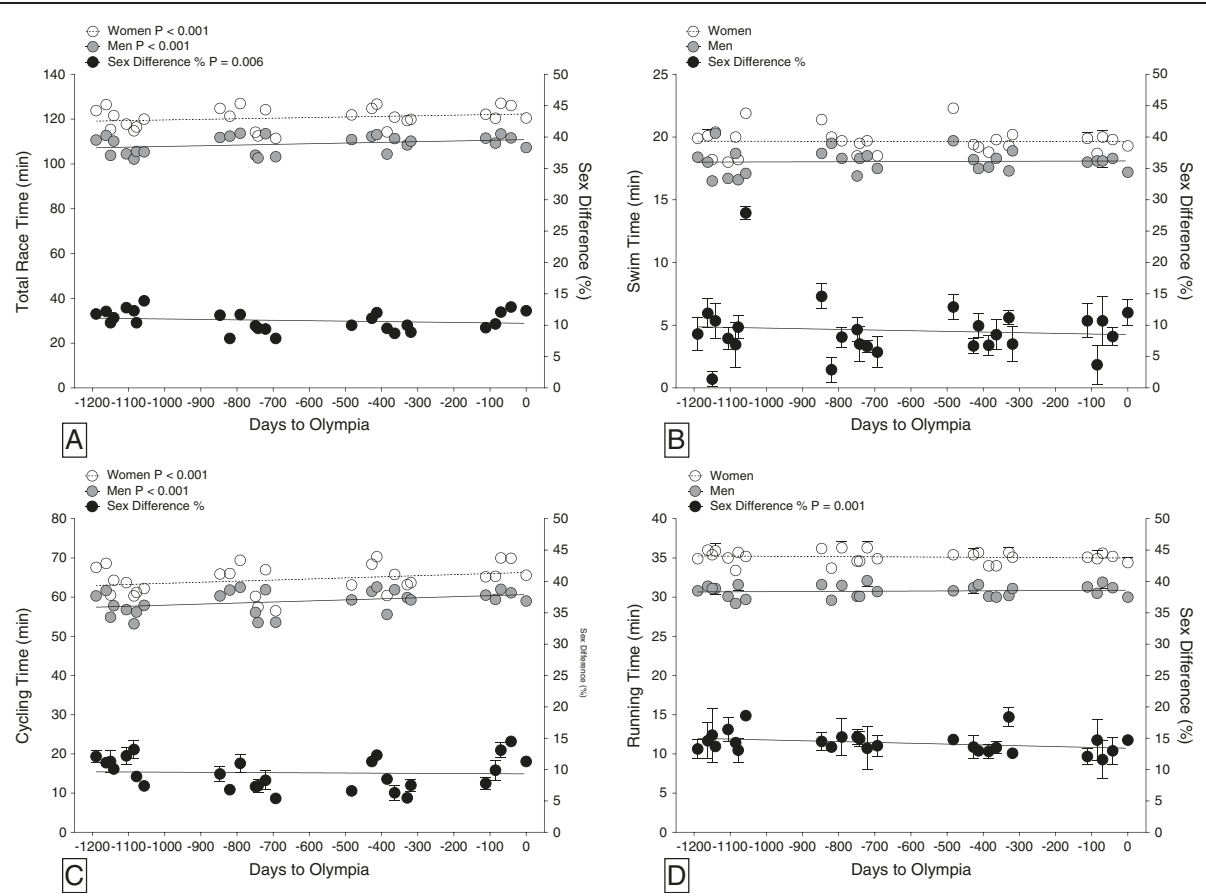

Figure 1 Change in performance at the ITU World Triathlon Series with corresponding sex differences from 2009 to 2012 . Overall race time (Panel A), swimming (Panel B), cycling (Panel C) and running time (Panel D). The time line is expressed in days before the Olympic Games.

\section{Decrease in sex difference in running and total time performance}

Interestingly, the results showed that the sex difference in performance decreased for running and overall race time but remained unchanged for swimming and cycling. By comparison, at the Ironman World Championship 'Ironman Hawaii' between 1983 and 2012, the sex difference for the annual top ten remained unchanged for swimming and cycling at $\sim 12.5 \%$ but decreased in running from $\sim 13.5 \%$ to $\sim 7.3 \%$ and in overall race time from $\sim 15.2 \%$ to $\sim 11.3 \%$ (Rüst et al., 2012b). For short-distance triathletes competing at national level between 2000 and 2010, the sex difference for the annual top five remained unchanged for swimming ( 15.2\%), cycling ( 13.4\%), running ( 17.1\%), and overall race time ( 14.8\%) (Etter et al., 2013). The present short-distance triathletes competing at

Table 2 Mean values \pm SD of swimming, cycling, running and total time for both women and men at the ITU World Triathlon Series with corresponding sex difference for each discipline

\begin{tabular}{|c|c|c|c|c|}
\hline Women & 2009 & 2010 & 2011 & 2012 \\
\hline Total time (min) & $119.5 \pm 3.4$ & $119.3 \pm 6.0$ & $121.1 \pm 3.8$ & $123.3 \pm 2.9$ \\
\hline Swimming split time (min) & $19.6 \pm 1.3$ & $19.6 \pm 1.0$ & $19.9 \pm 1.1$ & $19.5 \pm 0.6$ \\
\hline Cycling split time (min) & $63.5 \pm 3.0$ & $63.2 \pm 4.7$ & $65.0 \pm 3.2$ & $67.2 \pm 2.3$ \\
\hline Running split time (min) & $35.2 \pm 0.9$ & $35.2 \pm 1.1$ & $35.0 \pm 0.9$ & $35.1 \pm 0.7$ \\
\hline \multicolumn{5}{|l|}{ Men } \\
\hline Total time (min) & $106.9 \pm 3.6$ & $108.7 \pm 4.8$ & $1101 . \pm 2.7$ & $110.6 \pm 2.2$ \\
\hline Swimming split time (min) & $17.8 \pm 1.3$ & $18.2 \pm 0.8$ & $18.2 \pm 0.8$ & $17.9 \pm 0.5$ \\
\hline Cycling split time (min) & $57.4 \pm 2.6$ & $58.5 \pm 3.8$ & $60.0 \pm 2.2$ & $60.4 \pm 1.1$ \\
\hline Running split time (min) & $30.6 \pm 0.9$ & $30.8 \pm 1.0$ & $30.7 \pm 0.7$ & $31.0 \pm 0.9$ \\
\hline \multicolumn{5}{|l|}{ Sex difference } \\
\hline Total time (\%) & $11.9 \pm 1.2$ & $9.7 \pm 1.5$ & $10.0 \pm 1.1$ & $11.4 \pm 1.4$ \\
\hline Swimming split time (\%) & $10.6 \pm 7.5$ & $7.8 \pm 3.9$ & $9.0 \pm 2.9$ & $9.1 \pm 4.0$ \\
\hline Cycling split time (\%) & $10.8 \pm 2.1$ & $7.9 \pm 2.0$ & $8.3 \pm 2.5$ & $11.3 \pm 2.6$ \\
\hline Running split time (\%) & $14.9 \pm 2.7$ & $14.4 \pm 2.1$ & $14.1 \pm 2.2$ & $13.2 \pm 2.6$ \\
\hline
\end{tabular}


Table 3 Multi-level regression analyses for change in performance across years for women and men (Model 1) with correction for multiple participations (Model 2)

\begin{tabular}{|c|c|c|c|c|c|}
\hline Model & $B$ & SE (ß) & Stand. B & $T$ & $p$ \\
\hline \multicolumn{6}{|c|}{ Swim split women } \\
\hline 1 & $-3.442 e^{-005}$ & 0.000 & -0.013 & -0.209 & 0.835 \\
\hline 2 & $-3.442 e^{-005}$ & 0.000 & -0.013 & -0.209 & 0.835 \\
\hline \multicolumn{6}{|c|}{ Swim split men } \\
\hline 1 & $8.277 e^{-005}$ & 0.000 & 0.034 & 0.562 & 0.575 \\
\hline 2 & $8.277 e^{-005}$ & 0.000 & 0.034 & 0.562 & 0.575 \\
\hline \multicolumn{6}{|c|}{ Bike split women } \\
\hline 1 & 0.003 & 0.001 & 0.292 & 5.003 & $<0.001$ \\
\hline 2 & 0.003 & 0.001 & 0.292 & 5.003 & $<0.001$ \\
\hline \multicolumn{6}{|c|}{ Bike split men } \\
\hline 1 & 0.003 & 0.000 & 0.358 & 6.277 & $<0.001$ \\
\hline 2 & 0.003 & 0.000 & 0.358 & 6.277 & $<0.001$ \\
\hline \multicolumn{6}{|c|}{ Run split women } \\
\hline 1 & 0.000 & 0.000 & -0.081 & -1.338 & 0.182 \\
\hline 2 & 0.000 & 0.000 & -0.081 & -1.338 & 0.182 \\
\hline \multicolumn{6}{|c|}{ Run split men } \\
\hline 1 & 0.000 & 0.000 & 0.082 & 1.348 & 0.179 \\
\hline 2 & 0.000 & 0.000 & 0.082 & 1.348 & 0.179 \\
\hline \multicolumn{6}{|c|}{ Overall race time women } \\
\hline 1 & 0.003 & 0.001 & 0.227 & 3.820 & $<0.001$ \\
\hline 2 & 0.003 & 0.001 & 0.227 & 3.820 & $<0.001$ \\
\hline \multicolumn{6}{|c|}{ Overall race time men } \\
\hline 1 & 0.003 & 0.001 & 0.312 & 5.383 & $<0.001$ \\
\hline 2 & 0.003 & 0.001 & 0.312 & 5.383 & $<0.001$ \\
\hline
\end{tabular}

Table 4 Multi-level regression analyses for change in sex difference across years for women and men (Model 1) with correction for multiple participations (Model 2)

\begin{tabular}{|c|c|c|c|c|c|}
\hline Model & $B$ & SE (ß) & Stand. B & $\mathbf{T}$ & $p$ \\
\hline \multicolumn{6}{|c|}{ Swim split } \\
\hline 1 & -0.001 & 0.001 & -0.081 & -1.324 & 0.187 \\
\hline 2 & -0.001 & 0.001 & -0.081 & -1.324 & 0.187 \\
\hline \multicolumn{6}{|c|}{ Bike split } \\
\hline 1 & 0.000 & 0.000 & -0.044 & -.716 & 0.474 \\
\hline 2 & 0.000 & 0.000 & -0.044 & -.716 & 0.474 \\
\hline \multicolumn{6}{|c|}{ Run split } \\
\hline 1 & -0.001 & 0.000 & -0.210 & -3.511 & 0.001 \\
\hline 2 & -0.001 & 0.000 & -0.210 & -3.511 & 0.001 \\
\hline \multicolumn{6}{|c|}{ Overall race time } \\
\hline 1 & -0.001 & 0.000 & -0.167 & -2.772 & 0.006 \\
\hline 2 & -0.001 & 0.000 & -0.167 & -2.772 & 0.006 \\
\hline
\end{tabular}

international level reduced, however, the sex difference in running and overall race time between 2009 and 2012. The decrease in sex difference in overall race time might be due to the decrease in sex difference in running. However, the decrease in sex difference in running over the 2009-2012 period is difficult to explain and may be linked to different approaches of training in women and different race strategies (e.g. more energy saved in the cycling split).

The present results showed that the values of sex difference in Olympic distance triathlon performance for international elite triathletes were lower compared to those found for elite triathletes competing at national level (Etter et al., 2013). The sex differences were $9.1 \pm$ $5.1 \%$ versus $15.2 \pm 4.6 \%$ for swimming, $9.5 \pm 2.7 \%$ versus $13.4 \pm 2.3 \%$ for cycling, $14.3 \pm 2.4 \%$ versus $17.1 \pm 2.5 \%$ for running and $10.7 \pm 1.6 \%$ versus $14.8 \pm 1.8 \%$ for overall race time. The sex difference in cycling time was significantly $(P<0.001)$ lower than for swimming and running (Etter et al., 2013).

These findings suggest that international female short distance triathletes tended to reduce the gap with men. During the studied period, the sex difference varied between the disciplines with greater sex differences in running compared to cycling and swimming. In contrast, there was a smaller sex difference in running compared to cycling in elite long-distance triathletes in 'Ironman Hawaii' (Rüst et al., 2012b). This discrepancy in sex difference in running between short and longdistance triathlon is intriguing. However, the finding could be linked to the fact that in international longdistance triathlons such as Ironman triathlons drafting is forbidden in contrast to short distance triathlon where drafting is allowed. Pacing and drafting is essential for the race outcome in a short distance triathlon (Landers et al., 2008; Vleck et al., 2008). For example, the winner in a draft legal Olympic distance triathlon exited the water in the first pack in $90 \%$ of elite male and in $70 \%$ of elite female racers (Landers et al., 2008).

\section{Greater sex difference in running compared to cycling and swimming}

The results showed that in the 28 considered races of the ITU World Triathlon Series 2009-2012 including the 2012 Olympic Games, the sex difference was higher in running $(\sim 14.3 \%)$ compared to swimming $(\sim 9.1 \%)$ and cycling $(\sim 9.5 \%)$. Similar findings have been reported for recreational short-distance triathletes competing at national level (Etter et al., 2013) and non-elite Ironman triathletes (Lepers and Maffiuletti, 2011) where the sex difference in performance was greater in running compared to swimming and cycling.

However, in the present athletes at world class level, the absolute value of the sex difference in swimming was lower $(\sim 9.1 \%)$ compared to recreational short-distance 


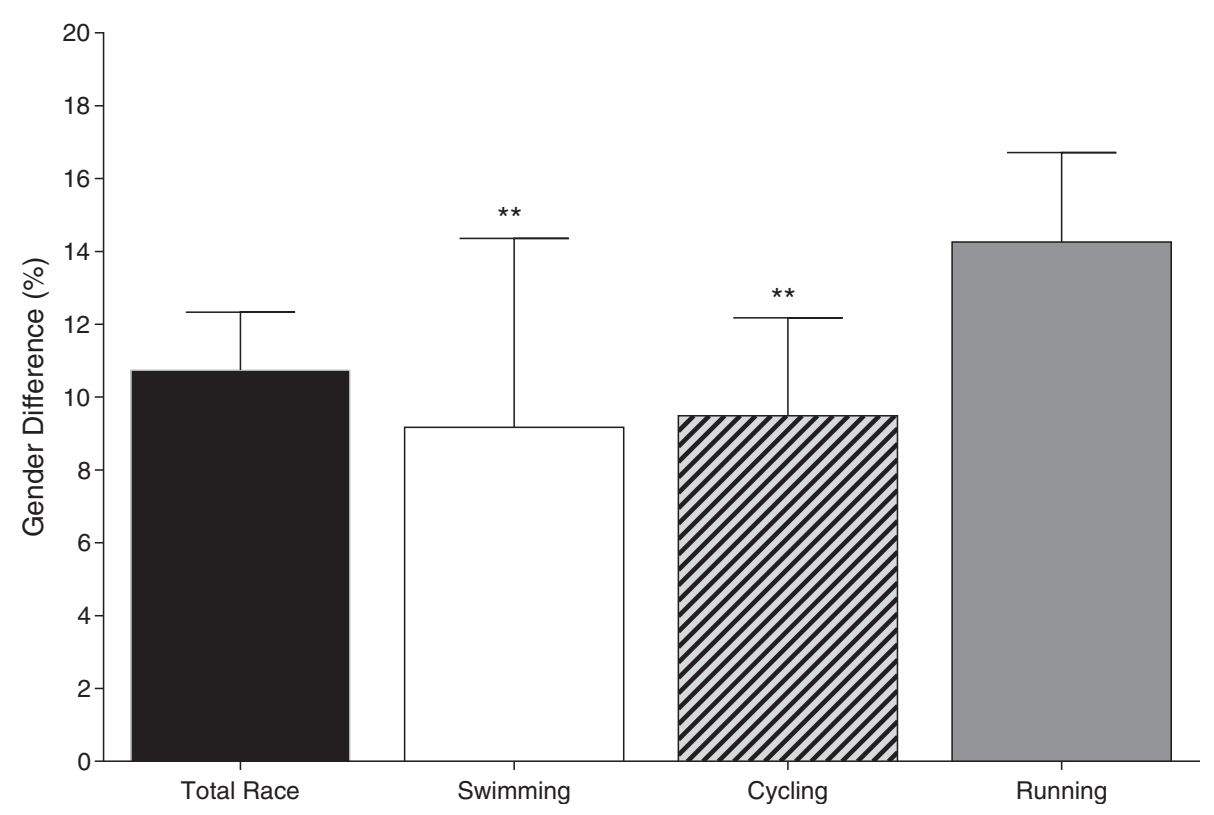

Figure 2 Mean $( \pm S D)$ sex difference in swimming, cycling, running and overall race times for the 2009-2012 period. ${ }^{* *}=P<0.01$; significantly different from running.

triathletes with $15.2 \pm 4.6 \%$ and elite Ironman triathletes with $12.1 \pm 1.9 \%$. Also for cycling and running, the absolute values of the sex difference were lower in the ITU World Triathlon Series $(9.5 \pm 2.7 \%$ and $14.3 \pm 2.4 \%$, respectively) compared to recreational short-distance triathletes at national level $(14.3 \pm 2.4 \%$ and $17.1 \pm 2.5 \%$, respectively) (Etter et al., 2013) and elite Ironman triathletes $(15.4 \pm 0.7 \%$ and $18.2 \pm 1.3 \%$, respectively) (Rüst et al., $2012 b)$. It seemed that the sex difference in performance in international level triathlons tended to be lower compared to triathlons at national level (Etter et al., 2013).

The higher sex difference in running compared to swimming and cycling might be due to drafting during the swimming and cycling splits. It has been shown that drafting can improve the performance in the subsequent split discipline in a short distance triathlon. Drafting during the swimming (Delextrat et al., 2003) and cycling part (Hausswirth et al., 1999, 2001) might select for a fast running split time in a short-distance triathlon. Hausswirth et al. (2001) showed that drafting continuously behind a lead cyclist allowed triathletes saving a significant amount of energy during the bike leg of a sprint triathlon and created the conditions for an improved running performance. Fast runners seemed to benefit most from drafting during cycling (Hausswirth et al., 1999). For the running split in short-distance triathlon, an appropriate pacing appeared to play a key role in high-level triathlon performance (Le Meur et al., 2009).

Differences in drafting between the sexes might be essential for race outcome. Male triathletes might benefit more cycling drafting then women because they tend to ride in larger packets (Landers et al., 2008). The men's running speed decreased significantly over the whole distance whereas women slowed down in the up- and down-hill sections (Le Meur et al., 2009). Vleck et al. (2006) demonstrated that both women and men in an elite Olympic distance triathlon ran faster over the first $993 \mathrm{~m}$ than most other run sections. However, no clear benefit of this strategy was apparent. In addition to drafting, the tactical approach in triathletes might be different. Vleck et al. (2006) showed that an inferior swimming performance may result in a tactic involving greater work in the initial stages of the cycling split which may substantially influence subsequent running performance. Because sex differences in running performance are greater for running compared to swimming and cycling, it could be suggested that elite male triathletes benefit more from cycling drafting than female athletes.

\section{Conclusion}

During the 2009-2012 period, the world's best female short-distance triathletes reduced the gap with male athletes in running and total triathlon performance. The sex difference in performance was greater for running ( 14\%) compared to swimming ( 9\%) and cycling $(\sim 10 \%)$. The influence of cycling drafting on running performance may differ between elite female and male triathletes. Future studies are required to clarify why the sex difference in running is greater compared to swimming and cycling in international short distance triathlon races with drafting. 


\section{Competing interests}

The authors declare that they have no competing interests.

\section{Authors' contributions}

CAR and BK drafted the manuscript, CAR performed the statistical analyses, MS collected all data, TR and RL participated in the design of the study and helped in interpretation of the results and to draft the manuscript. All authors read and approved the final manuscript.

\section{Author details}

${ }^{1}$ Institute of General Practice and for Health Services Research, University of Zurich, Zurich, Switzerland. ${ }^{2}$ INSERM U1093, Faculty of Sport Sciences, University of Burgundy, Dijon, France. ${ }^{3}$ Gesundheitszentrum St. Gallen, St. Gallen, Switzerland. ${ }^{4}$ Facharzt FMH für Allgemeinmedizin,

Gesundheitszentrum St. Gallen, Vadianstrasse 26, 9001 St. Gallen, Switzerland.

Received: 27 August 2013 Accepted: 17 December 2013

Published: 21 December 2013

\section{References}

Bentley DJ, Millet GP, Vleck VE, McNaughton LR (2002) Specific aspects of contemporary triathlon: implications for physiological analysis and performance. Sports Med 32:1-15

Bentley DJ, Cox GR, Green D, Laursen PB (2008) Maximising performance in triathlon: applied physiological and nutritional aspects of elite and non-elite competitions. J Sci Med Sport 11:407-416

Delextrat A, Tricot V, Bernard T, Vercruyssen F, Hausswirth C, Brisswalter J (2003) Drafting during swimming improves efficiency during subsequent cycling. Med Sci Sports Exerc 35:1612-1619

Etter F, Knechtle B, Bukowski A, Rüst CA, Rosemann T, Lepers R (2013) Age and gender interactions in short distance triathlon performance. J Sports Sci 31:996-1006

Etxebarria N, Anson JM, Pyne DB, Ferguson RA (2013) High-intensity cycle interval training improves cycling and running performance in triathletes. Eur J Sport Sci, 2013 Nov 9. [Epub ahead of print]

Gilinsky N, Hawkins KR, Tokar TN, Cooper JA (2013) Predictive variables for half-Ironman triathlon performance. J Sci Med Sport, 2013 May 22. [Epub ahead of print]

Hausswirth C, Brisswalter J (2008) Strategies for improving performance in long duration events: Olympic distance triathlon. Sports Med 38:881-891

Hausswirth C, Lehénaff D, Dréano P, Savonen K (1999) Effects of cycling alone or in a sheltered position on subsequent running performance during a triathlon. Med Sci Sports Exerc 31:599-604

Hausswirth C, Vallier JM, Lehenaff D, Brisswalter J, Smith D, Millet G, Dreano P (2001) Effect of two drafting modalities in cycling on running performance. Med Sci Sports Exerc 33:485-492

Knechtle B, Müller G, Willmann F, Kotteck K, Eser P, Knecht H (2004) Fat oxidation in men and women endurance athletes in running and cycling. Int J Sports Med 25:38-44

Knechtle B, Wirth A, Baumann B, Knechtle P, Rosemann T, Oliver S (2010a) Differential correlations between anthropometry, training volume, and performance in male and female ironman triathletes. J Strength Cond Res 24:2785-2793

Knechtle B, Wirth A, Baumann B, Knechtle P, Rosemann T (2010b) Personal best time, percent body fat, and training are differently associated with race time for male and female ironman triathletes. Res Q Exerc Sport 81:62-68

Knechtle B, Rüst CA, Rosemann T, Lepers R (2012) Age and gender differences in half-Ironman triathlon performances - the Ironman 70.3 Switzerland from 2007 to 2010. Open Access J Sports Med 3:59-66

Landers GJ, Blanksby BA, Ackland TR, Smith D (1999) Kinanthropometric differences between world championship senior and junior elite triathletes. Maximising Olympic Distance Triathlon Performance: A multi-disciplinary perspective, Proceedings from the Gatorade International Triathlon Science II Conference, Noosa, Australia, November 7-8, 1999., pp 74-87

Landers GJ, Blanksby BA, Ackland TR, Smith D (2000) Morphology and performance of world championship triathletes. Ann Hum Biol 27:387-400

Landers GJ, Blanksby BA, Ackland TR, Monson R (2008) Swim positioning and its influence on triathlon outcome. Int J Exerc Sci 1:96-105

Landers GJ, Ong KB, Ackland TR, Blanksby BA, Main LC, Smith D (2013) Kinanthropometric differences between 1997 World championship junior elite and 2011 national junior elite triathletes. J Sci Med Sport 16:444-449
Le Meur Y, Hausswirth C, Dorel S, Bignet F, Brisswalter J, Bernard T (2009) Influence of gender on pacing adopted by elite triathletes during a competition. Eur J Appl Physiol 106:535-545

Lepers R (2008) Analysis of Hawaii ironman performances in elite triathletes from 1981 to 2007. Med Sci Sports Exerc 40:1828-1834

Lepers R, Maffiuletti NA (2011) Age and gender interactions in ultraendurance performance: insight from the triathlon. Med Sci Sports Exerc 43:134-139

Lepers R, Knechtle B, Stapley PJ (2013) Trends in triathlon performance: effects of sex and age. Sports Med 43:851-863

Rüst CA, Knechtle B, Knechtle P, Rosemann T, Lepers R (2012a) Age of peak performance in elite male and female ironman triathletes competing in Ironman Switzerland, a qualifier for the Ironman world championship, 'Ironman Hawaii' from 1995 to 2011. Open Access J Sports Med 3:175-182

Rüst CA, Knechtle B, Rosemann T, Lepers R (2012b) Sex difference in race performance and age of peak performance in the Ironman Triathlon World Championship from 1983 to 2012. Extrem Physiol Med 1:15

Rüst CA, Knechtle B, Knechtle P, Pfeifer S, Rosemann T, Lepers R, Senn O (2013) Gender difference and age-related changes in performance at the long-distance duathlon. J Strength Cond Res 27:293-301

Vleck VE, Bürgi A, Bentley DJ (2006) The consequences of swim, cycle, and run performance on overall result in elite Olympic distance triathlon. Int J Sports Med 27:43-48

Vleck VE, Bentley DJ, Millet GP, Bürgi A (2008) Pacing during an elite Olympic distance triathlon: comparison between male and female competitors. J Sci Med Sport 11:424-432

doi:10.1186/2193-1801-2-685

Cite this article as: Rüst et al:: Performance in Olympic triathlon: changes in performance of elite female and male triathletes in the ITU World Triathlon Series from 2009 to 2012. SpringerPlus 2013 2:685.

\section{Submit your manuscript to a SpringerOpen ${ }^{\odot}$ journal and benefit from:}

- Convenient online submission

Rigorous peer review

- Immediate publication on acceptance

- Open access: articles freely available online

- High visibility within the field

- Retaining the copyright to your article

Submit your next manuscript at $>$ springeropen.com 